\title{
Advances in the treatment of lung cancer
}

\author{
TERESA YAE TAKAGAKI
}

In the history of medicine, the discovery of each new form of treatment is punctuated by the euphoria that accompanies initial advances, the disappointment of setbacks and the readaptation that leads to the treatment being taken up anew. Many innovative techniques are introduced only to be soon abandoned due to high morbidity or mortality, and then later redeemed through modification. One example in our experience, now used routinely in pulmonology, is lung volume reduction surgery, which became a viable option after the advent of surgical staples, reducing the chance of developing bronchopleural fistulas. In pulmonary carcinoma treatment, similar examples are found. In the initial treatment of small cell carcinoma, the treatment of choice was once surgery. However, it was observed that survival time did not improve, being 3 to 4 months in those undergoing surgery as well as in those left untreated. Radiotherapy, which increased survival to 6 months, then became the treatment of choice, and survival increased to 14 months after the introduction of systemic chemotherapy. ${ }^{(1)}$

In the past few decades, there has been little change in the treatment of small cell carcinoma. This is due to the high rate of response to the cisplatin-etoposide regimen. This success has impeded the testing of new drugs, which must present higher rates of response in relation to the existing regimen. In recent years, hopes were again dashed, this time regarding the drug irinotecan, a derivative of camptothecin, which is an inhibitor of the nuclear enzyme topoisomerase 1. Difficulties were encountered in the introduction of this drug into clinical practice due to the significant adverse effects of diarrhea and myelosuppression. ${ }^{(2)}$

In non-small cell lung cancer, surgery is still considered the only curative treatment. However, the majority of patients reach the stage of locally advanced disease or remote metastases, making surgery unfeasible. Consequently, millions are being invested in research to develop new products for systemic treatment. The motivation for such a substantial investment is found in the data presented by the World Health Organization, which estimates that the current lung cancer incidence rate is 10 million new cases per year, and that this rate will rise to 15 million new cases per year by 2020 . There are approximately 6 million cancer deaths per year, corresponding to $12 \%$ of all deaths, and lung cancer is the leading cause of cancer deaths (17\% of the total).(3)

Despite prevention programs and monitoring for early diagnosis, as well as the introduction of new surgical techniques, video-assisted thoracoscopy, conformal radiotherapy, brachytherapy, new chemotherapy regimens and new drugs, 5-year survival for patients with lung cancer has not changed in the last decades, still bordering on 14\%. ${ }^{(4)}$

Among lung cancer patients undergoing surgery, even among those submitted to surgery during the early stages of the disease, one-third experience postoperative relapse, presenting disease at remote sites. Such relapse leads to the need for adjuvant chemotherapy to control the micrometastases, which are probably present in the majority of patients with non-small cell lung cancer.

Given the magnitude of the pulmonary carcinoma problem, it is always the prime target of preclinical and clinical research into a newly discovered molecule. Every attempt is made to identify some treatment or new drug that might modify the natural history of this disease. In the 1980s, cisplatin was introduced. This brought new hope for chemotherapy treatment of pulmonary carcinoma since, until then, the available regimens produced response rates of only approximately $11 \%$ in patients with metastatic disease. ${ }^{(5)}$ Initially, it was difficult to give high doses due to significant emesis and nephrotoxicity, impeding its therapeutic use. However, after the discovery that serotonin antagonists such as ondansetron have an anti-emetic effect, cisplatin became the standard base of multidrug combinations used in chemotherapy. ${ }^{(6)}$

Chemotherapy for advanced non-small cell lung cancer was long considered ineffective and highly toxic. However, a meta-analysis comparing chemotherapy with support treatment found that survival was better among patients receiving chemotherapy. In randomized studies, in addition to improving quality of life, chemotherapy reduced symptoms and the length of hospital stays. ${ }^{(7)}$ 
In the last decade, second-generation chemotherapy agents known as taxanes appeared. Taxanes include vinorelbine and gemcitabine, which, when used in combination with cisplatin, produce higher rates of response than did previous combinations of cisplatin with mitomycin and vinblastine or with etoposide. ${ }^{(8)}$ However, the new combinations were similar among themselves, resulting in a 1-year survival rate of 33 to $43 \%$ among patients with advanced disease. ${ }^{(8)}$

In an attempt to improve survival in a group of stage-111A and stage-111B patients presenting early postoperative relapse, a randomized study was conducted in order to determine the role played by preoperative (neoadjuvant) chemotherapy. Early studies showed a significant improvement in survival. ${ }^{(9)}$ However, in more recent studies, the benefit of neoadjuvant chemotherapy was found to be restricted for patients with lymph node involvement in a single chain. It has been shown that the postoperative morbidity rate is high among patients having received preoperative chemotherapy, and that the mortality rate is elevated among those submitted to pneumonectomy. ${ }^{(10)}$

At the outset of the current decade, clinical trials of postoperative (adjuvant) chemotherapy were conducted in patients with stage $1 \mathrm{~B}$, stage 11 or stage IIIA cancer. These trials were based on the principal that pulmonary carcinoma is a systemic disease, and a systemic treatment would therefore be beneficial. ${ }^{(11-12)}$ These first studies found no benefit related to adjuvant therapy. However, in an issue the New England Journal of Medicine published in 2004, Arriagada et al. revealed the results of their contribution to the International Adjuvant lung Trial. ${ }^{(13)}$ The authors demonstrated that cisplatinbased chemotherapy provides an absolute benefit of 5\% over 5 years.

In 2004, a new cytotoxic drug, an antifolate known as premetrexed, was introduced. Another antifolate, methotrexate, was discovered in the 1940 s, but the mechanism of its action was not understood until 10 years later. New antifolates were discovered in the 1980s but were abandoned due to their nephrotoxicity and unpredictable myelosuppression. However, supplementation with vitamin B12 and folic acid produced a favorable therapeutic index, with little hematological toxicity, making antifolates a class of drugs that shows promise for the treatment of pulmonary carcinoma as well as mesothelioma. ${ }^{(3)}$
With the development of molecular biology techniques, the focus of research returned to the treatment of carcinoma in general. The first milestone was the beneficial response to imatinib, the tyrosine kinase inhibitor of the epidermal growth factor receptor (EGFR), seen in patients with chronic myeloid leukemia. ${ }^{(14)}$ Since there is no one molecular event that is common to all cases of pulmonary carcinoma, it is not expected that any of these target drugs will single-handedly transform its treatment. Heterogeneity of molecular events in non-small cell lung cancer and the relationship between this heterogeneity and new target drugs are demonstrated by the finding that EGFR mutation is only common in those few tumors that respond to EGFR inhibitors. Less than full understanding of the target drugs can lead to disappointing results in clinical studies. In the case of the angiotensin inhibitor bevacizumab, which was evaluated in the clinical trial phase, patients with epidermoid carcinoma and central tumors presented fatal hemoptysis, thereby precluding its use. ${ }^{(15)}$ It is currently believed that the target therapy should be more cytostatic and less tumoricidal, having the function of stabilizing, rather than reducing, the size of the tumor. The future of new therapies for solid tumors lies in predicting response and selecting target agents.

The need for new treatments is clearly evidenced in the results obtained with the drugs currently available. Therefore, any attempts to find active drugs that might improve the pulmonary carcinoma mortality rate are welcome contributions, such as the study conducted by Fischer et al. at the Universidade Federal do Rio de Janeiro (Federal University of Rio de Janeiro) and published in this issue of the Jornal Brasileiro de Pneumologia (Brazilian Journal of Pulmonology). The authors evaluated the effect of perillyl alcohol, a substance found in various plants.

Since the Fischer et al. study is preclinical, it could take years for the treatment evaluated to come into clinical use. However, increased understanding of cellular changes caused by substances that might later become chemotherapy agents can aid in understanding the nature of the tumor itself.

TERESA YAE TAKAGAKI

Chefe do Grupo de Neoplasia Pulmonar da Disciplina de Pneumologia do Hospital das Clínicas da Faculdade de Medicina da Universidade de São Paulo - USPSão Paulo (SP)- Brasil. 


\section{REFERENCES}

1. Johnson DH, Greco FA. Small cell carcinoma of the lung. Crit Rev Oncol Hematol. 1986;4(4):303-36.

2. Kudoh S, Nakamura S, Nakano T, Komuta K, Isobe T, Katakami N, et al. Irinotecan and etoposide for previously untreated extensive-disease small cell lung cancer: a phase 11 trial of West Japan Thoracic Oncology Group. Lung Cancer. 2005;49(2):263-9.

3. Newell DR. How to develop a successful cancer drugmolecules to medicines or targets to treatments? Eur J Cancer. 2005;41(5):676-82.

4. Shepherd FA. A targeted approach to reducing lung cancer mortality. J Clin Oncol. 2005;23(14):3173-4.

5. Buccheri G, Ferrigno D, Rosso A, Vola F. Further evidence in favor of chemotherapy for inoperable non-small-cell lung cancer. Lung Cancer. 1990;6(3-4):87-98.

6. Cosaert J, Quoix E. Platinum drugs in the treatment of non-small-cell lung cancer. Br J Cancer. 2002;87(8):82533.

7. Marino P, Pampallona S, Preatoni A, Cantoni A, Invernizzi F. Chemotherapy vs supportive care in advanced nonsmall-cell lung cancer. Results of a meta-analysis of the literature. Chest. 1994;106(3):861-5.

8. Schiller JH, Harrington D, Belani CP, Langer C, Sandler A, Krook J, et al. Comparison of four chemotherapy regimens for advanced non-small cell lung cancer. N Engl J Med. 2002;346(2):92-8.

9. Rosell R, Felip E, Maestre J, Sanchez JM, Sanchez JJ, Manzano JL, et al. The role of chemotherapy in early non-small-cell lung cancer management. Lung Cancer. 2001;34 Suppl 3:S63-74.

10.Martin J, Ginsberg RJ, Venkatraman ES, Bains MS, Downey RJ, Korst RJ, et al. Long-term results of combined-modality therapy in resectable non-smallcell lung cancer. J Clin Oncol. 2002;20(8):1989-95.

11. Pisters KM, Le Chevalier T. Adjuvant chemotherapy in completely resected non-small-cell lung cancer. J Clin Oncol. 2005;23(14):3270-8.

12. Scagliotti GV, Fossati R, Torri V, Crino L, Giaccone G, Silvano G, et al. Randomized study of adjuvant chemotherapy for completely resected stage 1,11 , or IIIA non-small-cell lung cancer. J Natl Cancer Inst. 2003;95(19):1453-61.

13. Arriagada R, Bergman B, Dunant A, Le Chevalier T, Pignon JP, Vansteenkiste J; International Adjuvant Lung Cancer Trial Collaborative Group. Cisplatin-based adjuvant chemotherapy in patients with completely resected nonsmall cell lung cancer. N Engl J Med. 2004;350(4):351-60.

14. Rosell R, Felip E, Garcia-Campelo R, Balaña C. The biology of non-small-cell lung cancer: identifying new targets for rational therapy. Lung Cancer. 2004;46(2):135-48.

15. Herbst RS, Onn A, Sandler A. Angiogenesis and lung cancer: prognostic and therapeutic implications. J Clin Oncol. 2005;23(14):3243-56.

16. Fischer JSG, Silva MSM, Paschoal ME, Gatass CR, Carvalho PC, Carvalho MGC. Efeito do álcool perílico na expressão gênica de células de adenocarcinoma de pulmão humano. J Bras Pneumol. 2005;31(6):511-5. 